\title{
Teaching new media composition studies in a lifelong learning context
}

\author{
Jill Jameson* and David Squires** \\ *University of Greenwich, email: j.jameson@gre.ac.uk \\ ***ing's College London
}

Governmental proposals for lifelong learning, and the role of Information and Learning Technologies/Information Communication Technologies (ILT/ICT) in this, idealistically proclaim that ILT/ICT empowers learners. A number of important governmental funding initiatives have recently been extended to the development of ILT in further education, which provides a particularly appropriate environment for lifelong learning. Yet little emphasis is given to more problematic research findings that students may be 'disarmed' in the process of learning to use technology. In the current global shift towards new forms of multimedia literacy, it is important to recognize human diversity by carrying out research focusing on the actual problems students face in adapting to Webbased technology as a new authoring medium. A case study into multimedia creative composition carried out with FE students in 1996-9 found that students tend to experience a problematic but potentially useful period of 'creative mess' when authoring in multimedia, and that 'scaffolding' strategies can be useful in overcoming this. Such strategies can empower students to derive benefits from multimedia composition if close attention is given to the setting up of the learning environment: a teachers' model for supporting novice hypermedia authors in further education is proposed, to assist teachers to understand and support the learning processes students may undergo in dynamic composition using new media technology.

\section{Introduction}

The government 'spin' on lifelong learning, as expressed in the Green Paper, The Learning Age (DfEE, 1998), and taken forward in the White Paper, Learning to Succeed (DfEE, 1999), emphasizes knowledge acquisition, skills development and student-centred flexible education and training. The aim of the government, as expressed in the summary document, Education and Training Development Agenda 2000-2001, is to 'help develop a "learning society" in which everyone, in whatever circumstances, routinely expects to learn and upgrade skills throughout life' (DfEE, 1998). Central to this idealistic notion is the 
view that continuous updating in ICT skills will play a vital part in the self-empowerment of individual learners. In support of this vision the government is funding ventures such as the Information and Communication Technologies (ICT) Learning Centres initiative - 'a new programme designed to help bridge the gap between those in society who have access to ICT and those who do not' (DfEE, 1999). Community Access to Lifelong Learning is a parallel New Opportunities Fund programme which is designed to encourage adult learning. It focuses on improving access to learning opportunities through the use of ICT.

In further education (FE), ICT ventures similar to the ICT Learning Centres initiative have recently been established. The visionary potential encompassed in an evolved conception of Information and Learning Technology (ILT, the ' $\mathrm{L}$ ' attempting with arguable effectiveness to include 'Communication' in a broader holistic agenda of 'Learning') had initially been well expressed in such documents as the Higginson Report (Higginson, 1996). This formative report outlined the need for continuous updating in ILT skills, and the potential for ILT/ICT to improve and extend access to learning and teaching in FE colleges in a lifelong learning context. Perhaps partly influenced by this work, government policy on ILT for further education has developed markedly in the past few years, culminating in an announcement by David Blunkett in December 1998 of a $£ 74$ million three-year government investment in ILT in FE. The 'National Learning Network' (NLN), the overall term for the range of actions comprising this initiative, will be enhanced by the $£ 100$ million that the Further Education Funding Council (FEFC) estimates colleges already spend annually on ILT. Together these two sums will support improvements to ILT including those in hardware and connectivity, staff and learning materials development and more effective learning, teaching and management of IT usage. A particularly formative time for ILT/ICT in further education is therefore now occurring, in which a national government development agenda is strongly laid out, and colleges have been asked to respond to government-allocated funds with an action plan for progressing ILT initiatives.

\section{ICT skills and lifelong learning in an FE context}

Although general further education colleges routinely offer a wide mix of both academic and vocational courses, there is a continuing tendency in FE to emphasize practical vocational skills in a learning environment rich with potential for the development of learning technology usage. However, there are problematic issues in the practical implementation of ILT/ICT in FE. There seems to be an assumption in some policy initiatives that through training and updating students in ICT skills, 'creative, enterprising scholars' (Hughes and Mager, 2000) will somehow emerge automatically. This assumption would imply that if, for example, we teach people how to use the Web, they will become the self-empowered knowledge-workers of tomorrow. Yet little or no emphasis in official government publications on lifelong learning is given to more problematic research findings such as those by Seale (1999), who argues that both the 'armament' and 'disarmament' of students is involved in learning to use technology, and that 'disarmament' through the use of learning technologies may place obstacles in the way of lifelong learning.

Recent perceptions of a multimedia-sponsored global shift towards the 'visualization of literacy' (Kress and van Leeuwen, 1996) highlight issues of armament and disarmament. 
New graphical and Web-based multimedia computing, as Tuman (1992) notes with concern, mark 'the beginning of a new form of literacy'. Street (1998) teases out such dawning concepts of one new form of literacy, suggesting a richer plurality can be discovered. While pointing out that 'new literacies' are formative in shaping children's relationship with their environment, Street argues, echoing Bakhtin (Street, 1998), that educators should challenge the 'centripetal' forces of an assumed hegemony of language. Through greater awareness of the variations of human diversity, both researchers and teachers can promote the 'heteroglossic character' of a recognition of 'multiple meanings' in a 'centrifugal . . . multi-languagedness' embracing the 'discourse varieties and communicative practices that elude . . . centralising tendencies' (1998). In Street's eloquent challenge to centralist assumptions that all uses of ILT/ICT for lifelong learning are automatically and transparently beneficial for everyone, there is, therefore, an emphasis on the benefits of particular, situated, 'heteroglossic' educational research closely focusing on potentially problematic, actual 'multi-languagedness' in practice.

Applying Street's idea of 'heteroglossia' to student multimedia authoring emphasizes, then, the local nature of practical exercises giving opportunities for student composition development. Multimedia composition is a useful skill for students to come to terms with in adapting to Web-based technology as a polymedial 'writing' vehicle appropriate to the twenty-first century. Updating in Web-based production skills enables students to understand this medium: it is important to ensure that students actively become part of the new 'electracy' - to use Ulmer's term for the literate use of digital technologies (Ulmer, 1999 , p.1). Such participation can harness students' potential to use ILT/ICT for the purpose of lifelong learning, and is particularly appropriate for returners to learning in FE.

However, FE learners new to multimedia composition may be faced with a significantly disempowering experience in the form of a period of conceptual confusion in varying ways in the process of authoring compositions. 'Disorientation' or the feeling of being 'lost in hyperspace' has already been much explored in the literature on hypertext/multimedia (for example, in Conklin, 1987). Nielsen (1995) is amongst those who tested the 'feeling lost' phenomenon, finding that, even with a small document, users became 'lost in hyperspace' and were 'often confused' about their location within the hypertext. What has been less explored, however, is the emergence of this phenomenon in FE student hypermedia composition in relation to 'new' media and literary studies. This paper reports on an FE case study which highlights ways in which in the process of multimedia authoring, students can be 'armed' to derive specific benefits if close attention is given to the setting up of the learning environment and the authoring task itself.

\section{A study of multimedia composition}

An exploratory case study on student multimedia composition was carried out in an FE college in 1996-9. The study built on student hypermedia/multimedia composition research done by Hay, Guzdial, Jackson, Boyle, and Soloway (1994); Lehrer (1993); Pohl, Prenner and Pergothafer (1995); Turner and Dipinto (1992); Dubowski and Orion (1998); and research by Wray, Chong, Phillips, Rogers, Walsh and Laird (1994). Research by Bereiter and Scardamalia (1987), the ideas of Sharples on writing as creative design (1996), 
and the 'Planner-Discoverer' authoring continuum identified by Chandler (1995) were also considered in the study.

The 'cases' in the study were the creative compositions produced by a small group of students who took part in multimedia production sessions in 1996/7 using the application HyperStudio. The study centred on the creative hypermedia composition work of four Access to HE mature FE students: Pearl, Laura, Tracey and Irene. They completed several phases of a hypermedia authoring project focusing on the generation of creative compositions. The five main compositions completed during the project were analysed using an eclectic methodology featuring quantitative as well as qualitative features.

\section{Quantitative investigations}

In the multiple-case design of the case study research, a statistical application of nonparametric tests, appropriate for the behavioural sciences in view of their usefulness with small samples (Siegel and Castellan, 1988), was carried out to measure four successive phases of student composition in a 'quasi-experimental process' of repeated measures. This kind of intensive work with small numbers, appropriate for investigative case study research in a new area, means that the quantitative results of the study were tentative findings that serendipitously emerged as part of the case study process. Although usefully replicated in the qualitative case-by-case analysis, the quantitative results need to be tested experimentally with larger numbers for greater statistical accuracy. Therefore the results reported below are for the purposes of indicating areas for future investigation.

The Friedman Test was applied to the average numbers of hypermedia links per screen in student compositions at each 'stage' for each composition, comparing the performance of each participant to find out whether there were significant differences between the ranks at the measurement points of these 'stages'. The Friedman Test revealed a $p<.028$ level of significance, indicating that in narrative-type compositions there was a significant difference in the numbers of links per screen over the time-phases.

Page's L Trend Test was then applied to students' work at four stages of composition in a variety of ways to see if the increasing number of links per screens across participants' work could be regarded as a significant trend, as opposed to just a difference at each measurement point. This revealed no significant trend for an increasing number of links per screen across case study participants (see Table 1).

From a further examination of the ranking across the four 'conditions', however, it was evident that the scores for 'conditions' two and three indicated that participants seemed to have been in a transitional stage of composition in these time-phases in which there was a degree of unresolved 'mess'. One could broadly regard this as a process in which the links were still being sorted out, and therefore numbers of links per screen might go up and down haphazardly. Page's L Trend Test was hence again applied, the 'conditions' two and three for all compositions being treated as a 'middle phase' together, the average of both representing this 'middle'. This gave three 'conditions': (1) beginning - Stage 1; (2) middle - Stages 2 and 3; and (3) end - Final Stage, 4 (see Table 2).

Page's L Trend Test applied again in a merged treatment for greater accuracy to these three 'conditions' gave a significance level of $p<.01$ (see Table 3 ) for the compositions, revealing 


\begin{tabular}{lcccc}
\hline Page's L - links/screens & Condition I & Condition 2 & Condition 3 & Condition 4 \\
\hline NH links to screens & $2.33(1)$ & $2.71(2)$ & $4.6(3)$ & $13.57(4)$ \\
FH links to screens & $1.33(1)$ & $1.5(2)$ & $1.83(3.5)$ & $1.83(3.5)$ \\
NW links to screens & $1.33(1)$ & $1.5(3)$ & $1.36(3)$ & $4.13(4)$ \\
IS links to screens & $0.67(2)$ & $1.5(1)$ & $2.07(3)$ & $6.58(4)$ \\
Ranking totals () & $(5)$ & $(8)$ & $(11.5)$ & $(15.5)$ \\
$L=109.78$ & & & & \\
\hline
\end{tabular}

Just outside the level of significance $L=111 p<.05$.

Table 1: Page's $L$ Trend Test no. of links per screen.

(Abbreviations NH= 'Nursery House'; FH= 'Fairy House'; NW= 'New Woods'; IS= 'Illa and the Statue' are for the names of students' compositions. Links/Screens $=$ the average number of hypertext links per screen created by students in each of the four stages of composing. The stages are treated as experimental conditions in a repeoted measures process).

\begin{tabular}{llcc}
\hline Page's L- links/screens & $\begin{array}{c}\text { Condition I } \\
\text { (Stage I) }\end{array}$ & $\begin{array}{c}\text { Condition 2 } \\
\text { (Ave Stages 2/3) }\end{array}$ & $\begin{array}{c}\text { Condition 3 } \\
\text { (Final) }\end{array}$ \\
\hline NH links to screens & $2.33(1)$ & $3.66(2)$ & $13.57(3)$ \\
FH links to screens & $1.33(1)$ & $1.67(2)$ & $1.83(3)$ \\
NW links to screens & $1.33(1)$ & $1.43(2)$ & $4.13(3)$ \\
IS links to screens & $0.67(1)$ & $1.25(2)$ & $6.58(3)$ \\
Ranking totals () & $(4)$ & $(8)$ & $(12)$ \\
$L=56$ & & & \\
\hline
\end{tabular}

Level of significance $p=<.001$.

Table 2: Page's $L$ Trend Test no. of links/screen with conditions $2 / 3$ merged.

a significant trend of increasing numbers of links to screens from the start of the composition process, through the confusion of the middle phase, to the final composition.

This indicated that although participants might go through a period of 'mess' in the middle phase of composition, the average numbers of links per screen created during this period would still be higher than in the first phase, and would be superseded again by the numbers of links per screen in the final composition phase.

Although Friedman's Test had revealed that the composition scores were significantly different at each phase, this did not emerge as a significant trend using Page's $L$ Trend Test if the four conditions were treated separately, but it clearly did if conditions two and three were measured together. There was thus a significant trend for the numbers of links per screen to increase across the phases, but this was only apparent if the middle phases were treated together as one condition. An identifiable period of 'creative mess' in the middle phases therefore seemed to occur in which the number of links per screen might go up or down haphazardly. This finally resolved itself into final compositions that were simultaneously more complex and more coherent, with a higher number of links to screens than at the start of the composition process. 


\begin{tabular}{lccc} 
Jill Jameson and Dovid Squires & \multicolumn{3}{c}{ Teaching new media composition studies in a lifelong learning context } \\
\hline Page's L - links/screens & $\begin{array}{c}\text { Condition I } \\
\text { (Stage 1) }\end{array}$ & $\begin{array}{c}\text { Condition 2 } \\
\text { (Ave Stages 2/3) }\end{array}$ & $\begin{array}{c}\text { Condition 3 } \\
\text { (Final) }\end{array}$ \\
\hline NH links to screens & $2.33(1)$ & $3.66(2)$ & $13.57(3)$ \\
FHNW links to screens & $1.33(1)$ & $1.43(2)$ & $4.13(3)$ \\
IS links to screens & $0.67(1)$ & $1.25(2)$ & $6.58(3)$ \\
Ranking totals () & $(3)$ & $(6)$ & $(9)$ \\
$L=42$ & & & \\
\hline
\end{tabular}

Level of significance $p=<.01$.

Table 3: Page's L Test no. links/screen: conditions 2/3 merged, FHINW.

Following the resolution of the period of students' confusion, an increase in the number of links across compositions in successive drafts indicated a growth in aptitude in the formation of links, and in students' understanding of the rhetorical and content appropriacy of linking. Over a period of several weeks, the numbers of links shot up in successive stages in all compositions (for example from 14 to 19 to 46 to 95 in Nursery House, from 18 to 23 in the case of Adventure Game, from 20 to 88 in Pop Quiz, and in the case of New Woods from 4 to 9 to 15 to 33) (see Figure 1). As the links increased in number, so the structural complexity of all of the compositions developed. From an initially simple structure of only three screens with two links, Illa and the Statue, for example, becomes a more intricately structured work with twelve screens and seventy-nine links. The dominant pattern is that compositions increased in the number of links, and in their scores for the three variables of 'originality', fluency and complexity, in a rise that peaks in the final phase (see Figure 1).

\section{Qualitative investigations}

A particular issue relating to this period of conceptual confusion, or phase of 'creative mess', was described in the interviews by students as the state of being 'lost' in the composition. All students noted this in different ways - Laura stated, 'I got lost all the time', while Pearl said, 'You get to a point where you need to have something to refer to and know exactly what's going where ... because I did have that problem, where I'd link up more than one page to one button.' One particular student was emotionally affected by these feelings of confusion in multimedia authoring:

I: I work better on paper, you know, because I'm nearly forty. I've been working on paper for much longer than I've been working on computers.. . I'd get a card, I'd make a card and then it would be gone. [Note: this refers to the 'cards' or multimedia screens constructed by students using HyperStudio] And I wouldn't know where it had gone to and ... and I couldn't get it back, and stuff like this, you know.. . I just felt like crying sometimes ... didn't know where things had kept disappearing to.

R: Now that's what I'm talking about. When people kind of get lost in this new environment. And so ... did you express to anybody what was happening then?

I: I spoke to Tracey about it. And I find - I think she's got the kind of brain that takes this sort of thing in a lot better - a lot quicker than I do. So speaking to her helped. 


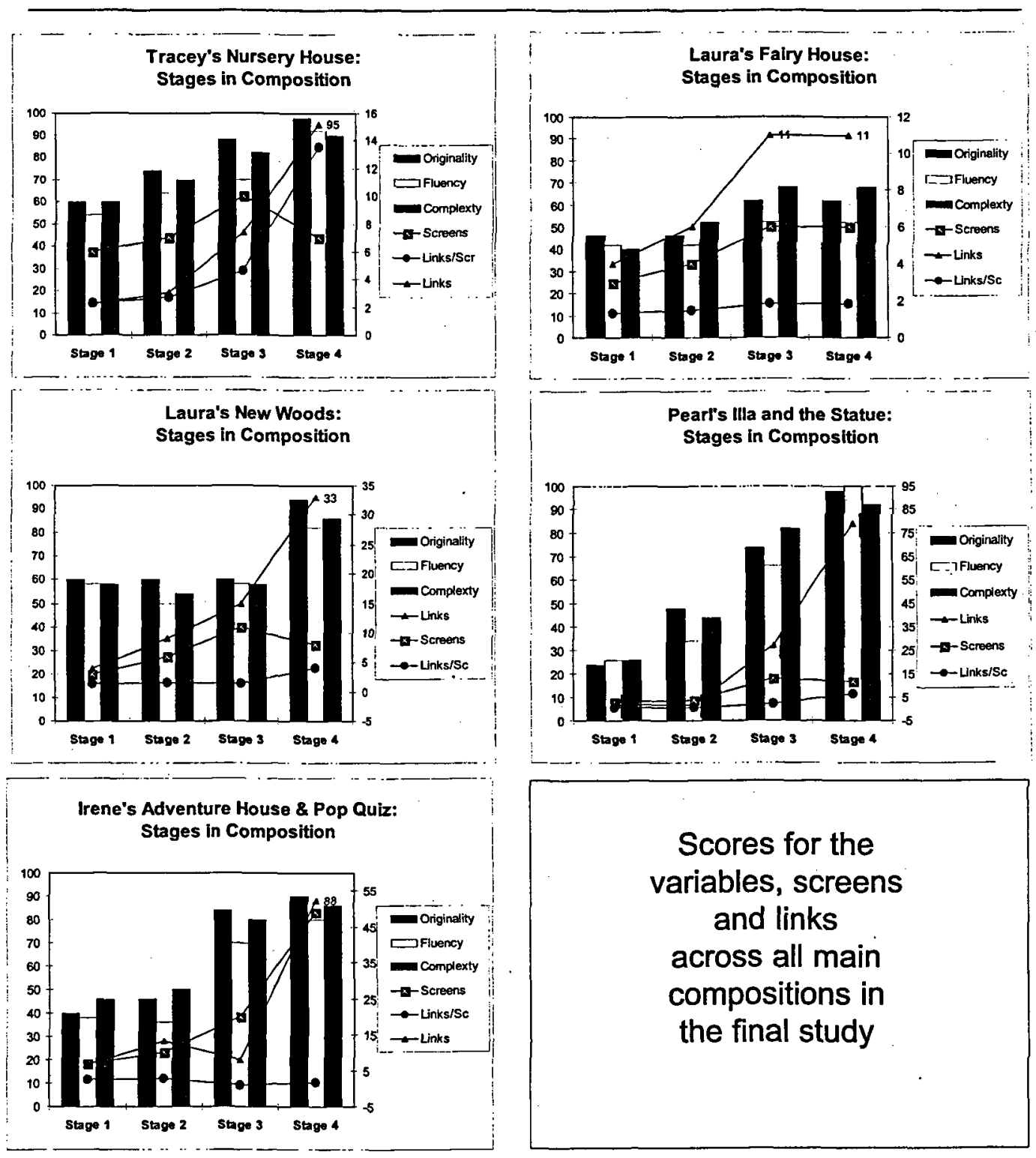

Figure 1: Scores for the variables, links and screens across all compositions.

R: So how did she help?

I: Well I just talked about what I was trying to achieve. And then we talked through it ... then she'd say, 'Oh well, it sounds like you should maybe try to do it like this.' And so we could talk it out and work out a good way to do it and then she got really interested in my ideas. And she wanted to help me to do mine, so we're kind of going to - I think we're going to get together and expand it together.

Interview with Irene, student, 21 July 
In a student multimedia composition environment, the period of disorientation in working one's way through multimedia may be a necessary part of the learning experience. Coming to terms with multimedia authoring can be a process of progressive self-empowerment, as students gradually adjust to the difficulties of the environment, and begin to understand how to work with it. Mayes, Kibby and Anderson (1990) note about hypertext that '[u]nder certain conditions (not all) disorientation in conceptual space may be regarded as a necessary prerequisite for depth of learning ... 'getting lost' may be regarded as a desirable or even necessary part of the process of structuring'.

\section{Results}

Research on student creative composition in multimedia has been relatively rare in view of the short history of computer-based hypermedia applications suitable for student production work. Examining students' work in a series of four repeated measures of composition stages, a critical finding of the study was the existence of a period of 'creative mess' in the authoring process, during which students need help to progress. This disorientating phase seemed to occur between the second and third stages of dynamic composition, in which the numbers of links created by students tend to go up or down haphazardly, compositions students were creating did not show an orderly progression in development and students could not fully envisage the shape of them.

The period of time varied according to students' capabilities, and was regarded by some students as a time of disorder in which they felt lost and depressed. The period was resolved as students sorted out the 'mess', deleting unnecessary screens and filling in missing links. The result, in narrative compositions, was a more elaborate, organized final work in which the numbers of links per screen were likely to be significantly higher than in any previous phase. In a case study involving intensive work with small numbers of students, these tentative statistical indications of a period of conceptual confusion were borne out by the qualitative analysis, in which students themselves suggested that a period of confusion had been resolved during the composing process.

This phase was therefore something students needed to overcome in order to progress with multimedia, but was also potentially productive for student authoring - a challenging but ultimately desirable phase for learners, as it seems to require them to expand their expressive capabilities to encompass the complexities of the medium. From this process, a beneficial 'cognitive residue' (Salomon et al., 1991) in expressive, creative design and problem-solving capability may result from the 'student-technology' partnership. Appropriate learning tools and techniques could usefully support messy exploration in hypermedia composition, since the results of this case study indicate that the period of 'creative mess' is both necessary and productive in enabling learners to expand their understanding of the hypermedia environment. Methods to assist the learner in working through this period, rather than to eliminate it, are required, since the findings of the study indicate that the elimination of this state would reduce the conceptual development undertaken in students' progression through the stages.

\section{Scaffolding strategies to overcome confusion and disorientation}

To overcome the confusion and disorientation students face during the period of 'creative mess', they need to engage with the process of composition in ways which call for the kind 
of 'knowledge transforming' strategies outlined by Bereiter and Scardamalia (1987). A number of the strategies undertaken by learners can be interpreted as scaffolding help of a variety of kinds. The zone of proximal development described by Vygotsky (1978) is related to the concept of scaffolding, in that this crucial zone is the difference between the actual level of mental development in the learner and the potential level of development when they are helped with guidance or through collaboration with more advanced learners 'what is in the zone of proximal development today will be the actual developmental level tomorrow'. Therefore, this concept of the 'zone of proximal development' led Vygotsky to propose that 'the only "good learning" is that which is in advance of development' (Vygotsky, 1978).

In terms of multimedia composition, the zone of 'creative mess' or aporia is a similar concept, directly related to hypermedia, of a precariously widened out potentiality for learning on the part of the student, who ventures into such messy exploration at the risk of confusion and further disorientation. The use of 'scaffolding' techniques is therefore crucial to assist the learner in this exploration, without minimizing its effectiveness. The concept of 'scaffolding' from tutors is an established methodology described by a number of researchers, but building 'fadeable scaffolding' into educational software is a new methodology for the 'learner-centred design' (LCD) of software that researchers Jackson, Krajcik and Soloway (1998) developed in the idea of 'Guided Learner-Adaptable Scaffolding' (GLAS). In this approach to software design, Jackson et al. note that 'the learner will . . . be in control of the changing and fading of scaffolding... The goal is for the student, with the software's help, to be able to take on some of the responsibility for his or her learning' (Jackson et al., 1998).

Jackson et al. differentiate between three different types of scaffolding: supportive scaffolding or 'support for doing the task'; reflective scaffolding, or 'support for thinking about the task'; and intrinsic scaffolding, or 'supports that.change the task, by reducing the complexity of the task and focussing the learner's attention (for example, training wheels on a bicycle ...) or by providing mechanisms for visualizing or thinking about a concept (for example, maps and models for visualization)' (Jackson et al., 1998). These three basic types of scaffolding were used by the learners in this case study in different ways. In terms of software support as a form of scaffolding, the only scaffolding software support was from the HyperStudio storyboard. Since HyperStudio is not a tutoring program directing the interactions of learners, but an open application for authoring in hypermedia, the 'fading' of scaffolding support was in all cases under the learner's control.

\section{Tutor and student peer support}

A supportive 'scaffolding' strategy used by students to help them sort out the confusion and difficulty of using HyperStudio was help from another person. Such help included the regular support given by the HyperStudio tutor, in all composition sessions, but it also included 'scaffolding' help from a more capable peer - in this case, Tracey, a self-appointed 'student expert' in the sense defined by Turner and Dipinto (1997). These researchers found that amongst the vital elements in enabling a successful student multimedia collaborative culture was the work undertaken by 'student experts', who 'were responsible for teaching their classmates how to do these things and for troubleshooting any problems' (Turner and Dipinto, 1997). Tracey provided important supportive and intrinsic scaffolding, students expressing that her help had been invaluable in enabling them to come to terms with the difficulty of the hypermedia task. 
The tutor provided supportive, reflective and intrinsic scaffolding to the students. In helping them carry out the task on a session-by-session basis, his support was crucial, and he worked one-to-one with the students to enable them to create their compositions. In terms of reflective planning, the tutor talked through with the students their composition plans, queried their ideas and helped them evaluate their work continuously. As regards intrinsic scaffolding, he reduced the complexity of the task on request, for example, to modify composition tasks. He also explained the idea of the concept map and encouraged students to visualize their work through this means.

\section{Storyboarding, diary-keeping and interview participation}

The HyperStudio storyboard was the first, and main, 'scaffolding' strategy frequently used by students to orientate themselves in the process of composing hypermedia, even though it only provides a limited linear overview. They used this device mainly for supportive scaffolding, as it was not sophisticated enough to provide much reflective or intrinsic scaffolding.

Diary completion and participation in interviews were both a means of reflective scaffolding. In the former case, students were encouraged to keep a diary on a weekly basis, to enable them to reflect on their work. In the latter case, the interview formed a summative evaluation and 'debriefing' from the project, in which students were encouraged in discussion with the researcher to analyse their work retrospectively in a final critique.

\section{Paper-based concept mapping}

The concept mapping strategy was used by learners for both reflective and intrinsic scaffolding: as a reflective scaffolding tool for planning the structuring of compositions, and to some extent as an intrinsic scaffolding tool, though students expressed that they did not need it after a certain point, voluntarily 'fading' it. Doing a paper-based concept map may therefore be a useful reflective and intrinsic planning tool to help students orientate themselves, though even without a concept map students may emerge from the tangled confusion of their work into greater clarity, particularly if given 'scaffolding' help by another person.

Once the period of initial confusion in using hypermedia is over, students may develop a capability of 'seeing' the work with a 'mental map', and are unlikely to need a concept map again for a composition with a manageable number of screens. Students in the study regarded the paper-based concept maps as a useful initial planning device, a 'beginning kind of thing', but were reluctant to revise them, seeing the updating process as irrelevant after the intermediate composition stages. The concept mapping exercise was therefore successful as a preliminary intervention in the case of three of the students in the research, though they chose voluntarily to 'fade' the use of this support over time. The conclusions of Pohl, Prenner and Purgathofer (1995) that 'inexperienced authors of hypermedia systems need special support to create non-hierarchical relationships and an adequate layout in their hypermedia document' and that 'the process of map construction helps learners to organise and structure their knowledge' were therefore to some extent replicated in the current study.

The use of dynamic online concept maps, automatically annotated by the hypermedia environment, would have been, arguably, easier for students. However, the conceptual challenge of a mapping task generated from and by the students themselves would not 
have been achieved in this short-term project, and for this reason an automated mapping environment was not given to the students, this 'omission design' to avoid the multimedia 'passivity trap' (Squires, 1997) being intended particularly to encourage the students to develop their own goals and to manage their own learning from the composition task.

Paper-based concept mapping was found to be deficient in modelling the actual activities students undergo in hypermedia composition, but was useful to 'kickstart' the students into deeper levels of composition. Potentially useful as an initial planning tool for hypermedia composition, paper-based concept maps may focus students on creating a comprehensible linking structure and help them overcome problems of being 'lost in hyperspace'. They can only be used, however, after students have developed some basic understanding and skill in hypermedia composition, and students' apparent reluctance to review and edit maps may need to be overcome. The use of concept maps can therefore be an initial enabling and empowering device to help learners cope with a difficult composition process in which navigation is particularly testing.

\section{Teaching model for teachers to support novice composers}

A model for use by teachers of novice hypermedia composition was developed from the case study, to indicate the stages in composition, and the factors that may be involved in teaching creative hypermedia authoring to novices (see Figure 2). This model depicts a simplification of the processes and strategies in the study, to outline for teachers the developing stages learners may undergo. In the centre of the model, the requirements for an effective hypermedia composition teaching environment are indicated. From this central block of text, four arrows radiate out, indicating that these elements are appropriate at all stages in composition, although some of them are particularly relevant to different stages. The relevance of these elements is demonstrated using a simple numbering scheme for the stages of composition. Around the circumference of the diagram, the four stages students in the study went through are displayed, indicating developing levels of maturity in composition, and the characteristics applying to each stage. The dominant aspects of the stages are summed up in statements arranged in a circular fashion around the central block of text. These are: (1) learning hypermedia skills; (2) zone of creative mess; (3) expanding links and screens; and (4) compacting, reflecting, evaluating. These statements sum up the process of composition observed and evaluated in the study. The model is put forward to assist teachers to understand some of the processes learners may undergo in composing hypermedia, indicating that a balance of cognitive strategies, discovery processes, physical and socio-cultural factors may be involved in the effective developmental evolution of novice authoring in hypermedia composition.

Specifically, the results of this study are directed at those interested in developing multimedia authoring, encouraging colleges to develop new media composition studies as part of their institutional ILT/ICT teaching and training programmes. A unique opportunity currently exists in FE to maximize the benefits of a continuing governmental focus on relatively greater investment in the sector: practical developments in expanding college conceptions of 'English and Communications' as a field of study to incorporate more substantial elements of new media teaching are necessary and should be achieved with careful attention to the learning environment set up for students. 


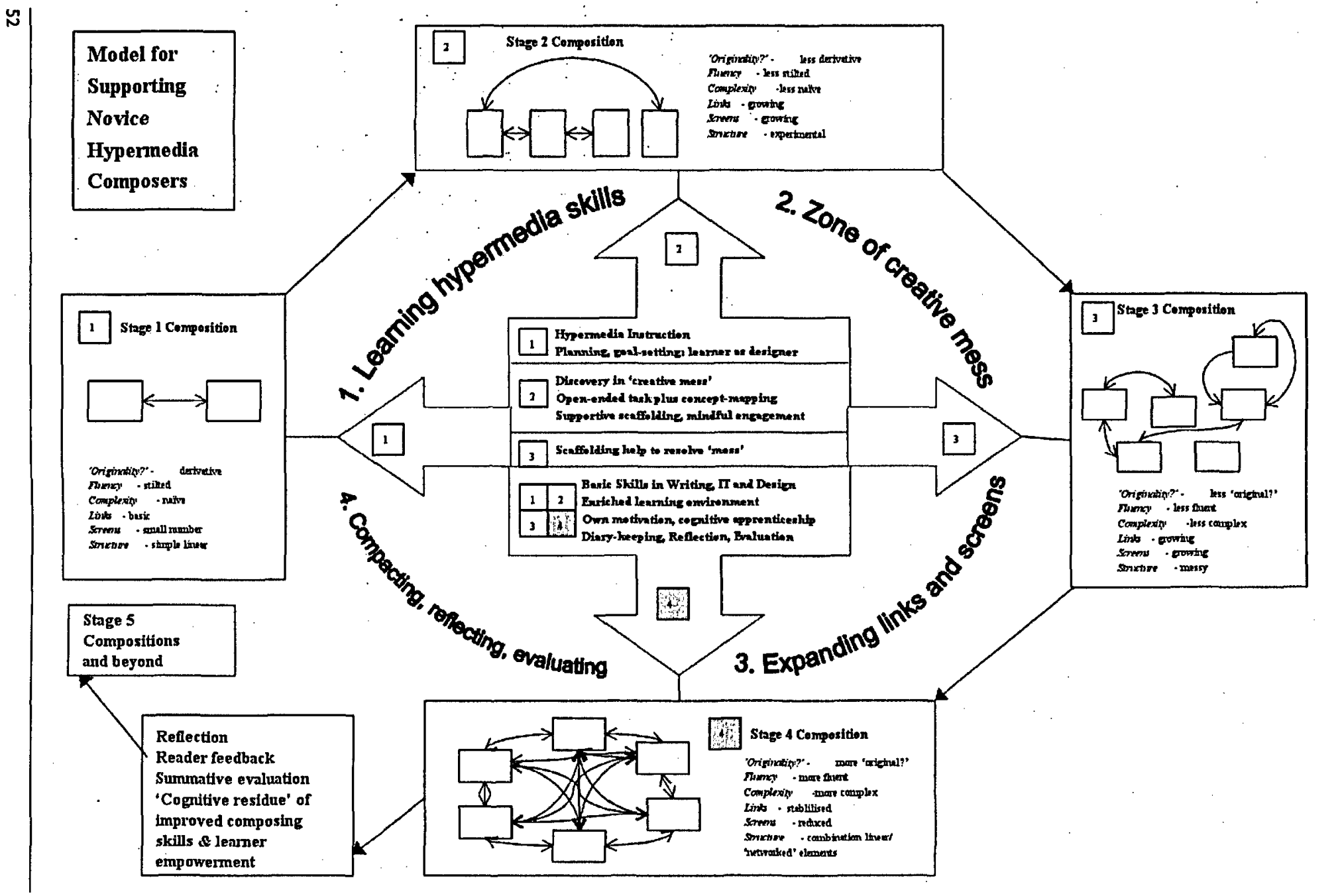

Figure 2: Teacher's model for supporting novice hypermedia composers. 
The current drive to use ILT in further education to improve students' capabilities for lifelong learning and to develop in learners 'innovation, self-reliance and creativity' is assisted by examining in detail problematic issues in the actual accomplishment of specific tasks such as multimedia authoring. The case study reported in this paper has concentrated on one particular problematic issue of student 'disarmament' in the use of ILT/ICT, proposing a solution developed through case study research. The tentative statistical results of this intensive case study research with a small number of adult FE students could be tested experimentally in work involving larger numbers. There is also a need for further more general detailed research work with students in the classroom across the range of ILT/ICT activities and skills in further education, to take forward a more real understanding of the actual problems learners face in using ILT/ICT productively and creatively in the twenty-first century.

The particular applicability of this study to the further education sector and the concept of lifelong learning relates to the fact that these novice student authors were adult returners to learning with specific requirements for support. More confident and experienced students at more advanced levels of higher education arguably may not require the careful construction of a learning environment with the multiple supportive features outlined here to foster a developing sense of self-empowerment in the process of multimedia authoring. In terms of improving access to lifelong learning through the use of ILT/ICT in further education, however, it is particularly relevant to examine and implement such ways of removing barriers to learning.

\section{Acknowledgements}

We would like to acknowledge the following for their help and support in this project: Laura, Tracey, Pearl, Irene, Bernie, the Media and Learning Resources staff in the College, the Staff Development Co-ordinator, and Bob Challis.

\section{References}

Bereiter, C. and Scardamalia, M. (1987), The Psychology of Written Composition, New Jersey: Lawrence Erlbaum Associates Inc.

Burbules, N. C. (1997), 'Aporia: Webs, passages, getting lost, and learning to go on', Philosophy of Education.

Carlson, P. A. (1990), 'The rhetoric of hypertext', Hypermedia, 2 (2), 109-31.

Chandler, D. (1995), The Act of Writing: A Media Theory Approach, Aberystwyth: University of Wales, Aberystwyth.

Conklin, J. (1987), 'Hypertext: an introduction and survey', Computer 20 (9), $17-41$.

de la Passardiere, B. and Dufresne, A. (1992), Adaptive Navigational Tools for Educational Hypermedia, Computer Assisted Learning: Proceedings of the 4th International Conference, ICCAL '92, Wolfville, Novia Scotia, Canada, Berlin/Heidelberg: SpringerVerlag.

Deleuze, G. and Guattarri, F. (1983), On the Line, New York: Semiotexte.

DfEE (1998), The Learning Age, London: DfEE. 
DfEE (1999), Learning to Succeed: A New Framework for Post-16 Learning, London: The Stationery Office

Dubowski, Y. and Orion, N. (1998), Evaluating the Educational Potential of Multimedia Authoring within the Framework of an Earth Science Curriculum - A Case Study, National Association of Research in Science Teaching (NARST), San Diego, Weizmann Institute of Science, Rehovoth, Israel.

Eklund, J. (1995), Cognitive Models for Structuring Hypermedia and Implications for Learning from the World-Wide Web, AusWeb95, Australia, Southern Cross University.

Gadamer, H. G. (1975), Truth and Method, New York: Seabury Press.

Garvey, C. (1982), Play, Shepton Mallet: Fontana/Open Books Original, Open Books Publishing Ltd.

Hannafin, M. J. and Land, S. M. (1997), 'The foundations and assumptions of technologyenhanced student-centred learning environments', Instructional Science, 25, 167-202.

Hay, K. E., Guzdial, M:, Jackson, S., Boyle, R. A. and Soloway, E. (1994), 'Students as multimedia composers', Computers in Education 23 (4), 301-17.

Higginson, G. (1996), Report of the Learning Technology Committee, Further Education Funding Council.

Hughes, M. and Mager, C. (2000), The Skills Agenda: Issues for Post-16 Providers, FEDA Comments Series, London: Further Education Development Agency (FEDA) Publications.

Jackson, S. L., Krajcik, J. and Soloway, E. (1998), The Design of Guided Learner-adaptable Scaffolding in Interactive Learning Environments, CHI98, Ann Arbor, MI 48109, USA, College of Engineering, School of Education, School of Information, University of Michigan.

Jonassen, D. H. and Grabinger, R. S. (1989), Problems and Issues in Designing Hypertext/Hypermedia for Learning, NATO Advanced Research Workshop on Designing Hypermedia for Learning, Rottenburg/Neckar: Springer-Verlag.

Kress, G. and van Leeuwen, T. (1996) Reading Images: The Grammar of Visual Design, London: Routledge.

Landow, G. P. (1989), 'Popular fallacies about hypertext', in D. H. Jonassen and H. Mandl (eds.), Designing Hypermedia for Learning, Berlin: Springer-Verlag, 39-60.

Landow, G. P. (1997), Hypertext 2.0: The Convergence of Contemporary Critical Theory and Technology, Baltimore, Maryland: The John Hopkins University Press.

Lehrer, R. (1993), 'Authors of knowledge: patterns of hypermedia design', in S. P. Lajoie and S. J. Derry (eds.), Computers as Cognitive Tools, Hillsdale, New Jersey: Lawrence Erlbaum Associates, Inc., 197-227.

Mayes, T., Kibby, M. and Anderson, T. (1990), 'Signposts for conceptual orientation: some requirements for learning from hypertext', in R. MacAleese and C. Green (eds.), Hypertext: State of the Art, Oxford, Intellect Limited, 121-9. ' 
Nielsen, J. (1995), Multimedia and Hypertext: The Internet and Beyond, London: AP Professional/Academic Press, Inc.

Peckham, M. (1967), Man's Rage for Chaos: Biology, Behaviour and the Arts, New York: Schocken.

Plato (1956), Meno. Protagoras and Meno, B. Radice. Harmondsworth: Penguin Books Ltd.

Pohl, M., Prenner, P. and Purgathofer, P. (1995), 'Hypermedia in education - monitoring the development of hypermedia documents', The Journal of the British Psychological Society's Special Group for the Teaching of Psychology, 4 (2), 142-52.

Salomon, G., Perkins, D. N. and Globerson, T. (1991), 'Partners in cognition: extending human intelligence with intelligent technologies', Educational Researcher, 20 (3), 2-9.

Seale, J. (1999), 'Learning technologies and the lifelong learner: armament or disarmament?', ALT J, 7 (2), 61-7.

Sharples, M. (1996), 'An account of writing as creative design', in C. M. Levy, and S. Ransdell (eds.), The Science of Writing: Theories, Methods, Individual Differences, and Applications, Mahwah, New Jersey: Lawrence Erlbaum Associates Inc.

Seigal, S. and Castellan, N. J., Jr. (1988), Non Parametric Statistics for the Behavioural Sciences (second edition), Singapore: McGraw-Hill Book Co.

Street, B. (1998), 'New literacies in theory and practice: what are the implications for language in education?', Linguistics and Education, 10 (1), 1-24.

Squires, D. (1997), 'Can multimedia support constructivist learning?', Teaching Review, 4 (2), 10-17.

Tuman, M. C. (1992), Word Perfect: Literacy in the Computer Age, Pittsburgh Series in Composition, Literacy and Culture, D. Bartholomae and J. Ferguson Carr (eds.), Pittsburgh, Pa: University of Pittsburgh Press

Turner, S. T. and Dipinto, V. M. (1997), 'Peer collaboration in a hypermedia learning environment', Journal of Research on Computing in Education, 28 (5).

Turner, S. V., and Dipinto, V. M. (1992), 'Students as hypermedia authors: themes emerging from a qualitative study', Journal of Research in Computer Education, 25, 187-99.

Ulmer, G. (1999), The Invention List: Website for Newsgroup University of Florida, http://web.elf.edu/ gulmerl.

Vygotsky, L. S. (1978), Mind in Society: The Development of Higher Psychological Processes, Cambridge, Mass.: Harvard University Press.

Wray, R. E. I., Chong, R., Phillips, J., Rogers, S., Walsh, W. and Laird, J. (1994), 'Organising information in mosaic: a classroom experiment', SDGIIT 94. 